\title{
Caregiver Burden in Multiple Sclerosis: Recent Trends and Future Directions
}

\author{
Rebecca Maguire $^{1} \cdot$ Phil Maguire ${ }^{2}$ \\ Published online: 22 May 2020 \\ (C) Springer Science+Business Media, LLC, part of Springer Nature 2020
}

\begin{abstract}
Purpose of Review In spite of recent advances in treatment, many people with multiple sclerosis (MS) require ongoing care and support. Informal caregivers can experience burden as a result of their role, with possible implications for quality of life (QOL). We review recent research examining MS caregiver experience to (1) understand current risk factors for caregiver burden and (2) identify possible strategies for increasing carer well-being.

Recent Findings MS caregiver experience is highly variable and can be predicted by a variety of care recipient, caregiver and contextual factors. Burden is not the only characteristic associated with care, with positive consequences also reported. Emerging research suggests a number of ways in which carers can be better supported.

Summary Identifying and meeting the needs of MS caregivers offers the best way of delivering tailored support. Future research should focus on the development of psychosocial supports, while acknowledging the needs of those caring for different MS patient populations.
\end{abstract}

Keywords Multiple sclerosis $\cdot$ Caregivers $\cdot$ Informal carers $\cdot$ Burden $\cdot$ Social support $\cdot$ Psychological adjustment

\section{Introduction}

Multiple sclerosis is a chronic, and often progressive, neurological disorder, which can lead to a range of adverse effects, including problems with vision, balance, mobility, cognition, bladder and sexual functioning [1]. While typically presenting in early to middle adulthood, advances in diagnostic tools has meant that patients are now being identified at an earlier stage [2], with a growing proportion of MS cases being diagnosed in childhood or adolescence [3]. Recent figures suggest that, overall, the number of people living with MS is increasing internationally $[1,4]$.

Fortunately, a diagnosis of MS is not as bleak today as it was in previous decades. While a variety of symptoms may be

This article is part of the Topical Collection on Demyelinating Disorders

Rebecca Maguire

Rebecca.maguire@mu.ie

1 Department of Psychology, Maynooth University, Maynooth, Co. Kildare, Ireland

2 Department of Computer Science, Maynooth University, Maynooth, Co. Kildare, Ireland experienced by patients [5], the development and availability of a wide range of treatments has meant that people with MS (PwMS) are now better placed to manage their condition [1]. Nevertheless, although many PwMS continue to live independently and maintain a high quality of life (QOL), others require ongoing care and support. Often, family members and friends are required to deliver this support, taking on the role of "informal caregivers" $[6,7]$. Their role in providing care is critical in helping to meet the gaps left by deficits in formal healthcare supports, yet the challenges of providing care to PwMS are frequently overlooked [8].

A large body of literature suggests that MS caregivers, and indeed those caring for other chronic illness patients, are at risk of experiencing considerable "burdens" [9]. While quantifying and conceptualising burden can be difficult, owing to various definitions and measures in existence, the consensus is that this can have a detrimental impact on caregiver QOL and well-being $[10,11,12 \bullet \bullet]$. For example, a recent report found that caring for PwMS can negatively influence caregiver physical and mental health, as well as impacting on their financial situation and employment status [13]. Other work, however, suggests that caregiving involves more than simply the experience of burden, stress and/or strain and may indeed lead to positive consequences $[14 \cdot, 15]$. 
In order to better support MS caregivers in their role, understanding their current experiences and needs is vital. In this report, we review recent trends in MS caregiver research (2014-2019), highlighting some key factors that may increase the risk of caregiver burden, as well as possible strategies for enhancing QOL for those affected by MS. We discuss how contemporary research points to ways in which caregivers can be better supported in their roles, decreasing the risk of burden and, consequently, enhancing well-being for both themselves and their care recipients.

\section{Characteristics of MS Caregivers}

Before attempting to understand the experience and needs of MS caregivers, it is important to get an estimate of the number of PwMS requiring care today. This in itself is a difficult feat, as PwMS can vary greatly in their care needs, with fluctuations in need occurring over the time course of the disease and with disease type. Few countries collect statistics on the number of MS caregivers [16]; however, one recent large-scale analysis with almost 17,000 PwMS suggested that $46 \%$ received informal care from family members [17••]. While this figure is broadly consistent with other estimates [18], some studies report that as many as $58 \%$ of PwMS receive informal care [7], with requirements for care increasing considerably with increasing levels of disability. Given an estimate of over 2.2 million cases of MS worldwide [19], we can therefore extrapolate that there are more than one million MS caregivers globally.

Currently, informal care for PwMS is most commonly provided by spouses, with recent estimates of spousal care ranging from 53 [20] to 70\% [6]. As there are a disproportionately higher number of women diagnosed with MS (a ratio of 2.8:1 [21]), one might expect a higher proportion of male MS caregivers overall. The gender breakdown of MS caregivers, however, varies considerably across contexts. While some studies, as expected, report a higher proportion of male carers [22••, 23 ], others suggest females are more likely to take on the caregiving role [20, 24-26]. In one study based in Mexico, female MS caregivers reported spending nearly twice as much time caring as male caregivers ( 79 vs. 48 h per week), having also been in their caring role for nearly three times as long [26]. These variations may be linked to gender role expectations and are reflective of the wider caring literature, which indicates that women take on the majority of caring responsibilities [14•]. Given shifts towards fuller female participation in the workforce, coupled with blurring gender roles, one might expect the proportion of MS male caregivers to increase over the coming years, though this is likely to be dependent on cultural norms.

MS caregivers also vary considerably in age, depending on their relationship to the care recipient. As needs for care tend to increase with age, with older PwMS experiencing greater levels of disability [27], spousal carers may be old themselves and have existing health complications. The experience of physical co-morbidities can make caring more difficult [28], meaning that this group is particularly vulnerable to healthrelated burdens from care. In contrast, there are also many young caregivers who take on the role of supporting parents with MS [29-31], as well as parental caregivers of those with paediatric MS [32-34]. These diverse groups may experience a different set of challenges and needs, which is often reflective of their stage of life [35]. Appreciating the diversity in MS carer sociodemographics is an important first step when considering how best to tailor supports.

\section{Understanding MS Caregiver Burden}

A generally accepted finding is that caring for PwMS has associations with carer QOL and well-being [12••]. For example, one recent study found that MS carers had lower healthrelated QOL than non-carers [20], with 68\% experiencing pathologic anxiety and 44\% experiencing pathological depression, using the Hospital Anxiety and Depression Scale (HADS). MS carers have also been found to experience elevated levels of fatigue, depression and anger [36]. This is in line with recent findings from other disease domains, where caring has been reported to impact negatively on caregiver health [37, 38] and QOL [39].

The concept of burden is frequently mentioned in this context, with any decreases in QOL attributed to caregiver burden and/or care-related stress [12••, 23]. It is important to acknowledge, however, that burden can be defined in many different ways [40], so caution should be exhibited when attempting to make direct comparisons across studies in this area. A critical distinction, for example, is the difference between objective and subjective burden as it relates to caregiving.

Objective burden is typically quantified in terms of the time taken to carry out care-related tasks. For example, MS caregivers may be required to assist with basic activities of daily living (ADL) and instrumental ADL, as well as providing social-practical and psycho-emotional care for their care recipients [41]. All of these responsibilities require considerable time commitments, with MS caregivers spending an average of $6.5 \mathrm{~h}$ a day dedicated to caring tasks [6]. Although this may not be as high as reported by caregivers of some other neurological conditions [9], such responsibilities clearly have implications for other domains of life, such as employment. As evidence of this, $40 \%$ of MS carers reported missing work in the past year due to caring responsibilities [22••], with $24 \%$ either reducing or stopping work completely [18]. This may be even more difficult for parental carers of children or adolescents with MS, who may not only have to take time off 
work but are also required to juggle other responsibilities, such as care of other children $[42,43]$.

Objective burden is directly associated with the overall cost of caring, both in terms of economic cost and losses in productivity, and is consistent with the finding that caregiving for PwMS is associated with considerable economic burdens, even in a population with low levels of physical disability [44]. Nevertheless, this cost does not always lead to decrements in caregiver well-being [6]. Subjective burden, in contrast, which refers to the caregiver's own perception of the impact that caring has on their daily life, appears more strongly related to well-being [6]. While more time spent caring is associated with greater likelihood of experiencing subjective burden [45], a high objective burden from caring for PwMS is not always associated with negative perceptions [41]. This fits with recent findings from the broader literature on caregiving. For example, our recent work with a representative sample of European carers found that the majority reported being happy with the amount of time they spent caring [14•].

Subjective burden is, nevertheless, a common experience for MS caregivers [6]. Reflecting this, the challenge most commonly reported by carers is the emotional strain associated with caring for PwMS [13]. This type of burden also has strong associations with mental health, including caregiver depression [23, 46]. Not all studies have revealed consistent findings, however, with one recent study surprisingly finding mental QOL to be positively associated with burden [28].

While objective burden is somewhat easier to quantify, a number of different tools exist for measuring subjective caregiver burden in MS [40, 47]. Commonly employed measures include the Zarit burden scale [48, 49], the CareQoL-MS [50], the caregiver reaction assessment [51] and the Kingston caregiver stress scale [52]. These may lead to differences in the reported prevalence of MS caregiver burden, with estimates ranging from mild to intense across studies $[20,22 \bullet \bullet, 46]$. The use of standardised measures, however, can be useful when attempting to compare the burden experienced by MS carers to those caring for other chronic illness groups. For example, a recent review suggests that subjective burden as measured by the Zarit burden scale was higher among MS carers than those in other caring populations [40].

Though such work clearly shows how the experience of burden can impact on carer well-being, it is also apparent that this can affect the well-being of the care recipient too. In other populations, it has been shown that carers reporting poorer health and depressive symptoms were less likely to provide high-quality care for their family members [53]. In the case of MS, one recent study showed how perceived carer burden mediated the relationship between patient's experience of depressive symptoms and their disability level and physical QOL [54]. Identifying ways of decreasing burden, and in particular subjective burden, is therefore important for ensuring the well-being of both the caregiver and care recipient. In the following section, we collate contemporary research findings to suggest some ways in which this may be achieved.

\section{Possible Determinants of Caregiver Burden}

Table 1 summarises some of the key factors which may influence subjective MS caregiver burden, as well as MS caregiver experience more generally, based on recent research trends. We have categorised these factors according to their associations with (1) the care recipient, (2) the caregiver and (3) the wider social and contextual environment. Recent models have attempted to explain caregiver burnout by adopting a similar approach, acknowledging the role of the caregiver, caregiving setting and sociocultural context [55]. We suggest that, in considering the development of any supports for MS caregivers, these diverse set of factors should be carefully acknowledged.

\section{Risk Factors Associated with the Carer and Care Recipient}

Unlike caring for some other chronic conditions, MS caregiver burden is not directly related to disease duration. While care needs for PwMS typically become greater over time, the wide variability in MS progression means that time since diagnosis, in itself, is not a reliable predictor of burden. Rather, burden appears to be associated with the extent of disease progression. A consistent finding is that higher caregiver stress and burden are associated with higher levels of disability, such as increasing scores on the expanded disability status scale (EDSS) [6, 7] or problems walking [45, 56-58]. Unsurprisingly, carer burden is also higher for those caring for people with progressive forms of the disease (both primary and secondary progressive MS), in comparison to those with relapsing remitting MS [22••].

With increasing levels of disability comes a greater likelihood of PwMS experiencing a range of symptoms [5], each of which have differing relationships with caregiver burden. Aside from known associations between burden and mobility/disability, recent studies have explored how cognitive problems in PwMS relate to caregiver stress and strain. This work reflects more broadly a greater acknowledgement of the prevalence of cognitive problems in MS [46]. Caregiver burden has been shown to be predicted by higher dysexecutive function [6] and cognitive/neuropsychiatric problems [57], while a comprehensive analysis of cognitive functioning in PwMS found that lower working memory capacity, information processing speed, executive functioning and verbal fluency were all associated with worse caregiver health-related QOL [59, 60]. Notably, cognitive problems predicted caregiver depressive symptoms, independently of other MS-related symptoms 
Table 1 Factors associated with caregiver burden in MS

\begin{tabular}{ll}
\hline & Risk factor \\
\hline Care recipient (PwMS) characteristics & Type of MS (PPMS/SPMS or RRMS) \\
& Level of disability \\
& Experience of symptoms (e.g. cognitive problems) \\
& Psychological distress \\
Caregiver characteristics & Relationship to PwMS \\
& Gender \\
& Physical health \\
& Income/education \\
Social or contextual factors & Psychological appraisals \\
& Time spent caring (objective burden) \\
Social support \\
Provision of information \\
Healthcare services support
\end{tabular}

[59]. Developing supports for helping both PwMS and their caregivers deal with the cognitive consequences of MS may therefore be particularly beneficial in reducing burden.

Aside from the health status and functioning of the care recipient, certain MS caregivers may themselves be at greater risk of experiencing burden based on their own sociodemographic characteristics. Burden experience may be also influenced by the nature of the relationship to the care recipient. As mentioned previously, informal care is most commonly delivered by spouses. This group can be particularly vulnerable to strain, which can, in turn, impact on relationship satisfaction [61]. Conversely, young carers of adult parents [29], and parental carers of children or adolescents with MS [16], report different needs, which may lead to different experiences of burden.

A number of studies suggest that female caregivers tend to experience more strain and psychological distress than male caregivers [22••, 26, 62], although this may be accounted for by higher levels of objective burden, or time spent caring, by female carers [26]. Recent qualitative work supports the idea of gender differences in the MS caregiving experience. For example, male caregivers are more likely to experience physical concerns from caregiving [22••], as well as problems with social expectations, such as those relating to marital relationships and gender roles [63]. They also experience more fears for the future, which, as later discussed, is an important factor to consider when supporting those affected by MS. Females, in contrast, express more need for emotional support [12••] and do also report having greater social support [62]. Taken together, this work suggests that gender identity may need to be acknowledged when tailoring appropriate caregiver supports.

In keeping with earlier research and also the broader caregiver literature $[14 \bullet, 64]$, lower financial status is also associated with higher burden and health-related QOL [20], with low-income caregivers being particularly vulnerable to caregiver stress. The experience of personal health concerns can also lead to greater burden in MS caregivers, this being a particular concern for older caregivers who are more vulnerable to caregiver strain $[28,57]$. While not an exhaustive overview of possible contributory factors to burden, these findings suggest that certain caregivers may be in need of greater support.

\section{The Role of Psychosocial Factors in Caregiver Burden}

Recent work highlights the range of psychological difficulties that can be experienced by both PwMS [65, 66] and their caregivers [20]. The high prevalence of psychological problems in these groups may, in part, be due to the unpredictable nature of the disease, especially in the case of relapsingremitting MS, where care needs may vary considerably. This unpredictability can also give rise to the experience of uncertainty [67], which can make planning, in both the short and long term, difficult. Experiences of uncertainty may, in turn, lead to the experience of caregiver burden, with higher carer anxiety having been found to be associated with higher burden across a number of studies [20,68].

Borrowing from the cancer literature, we know that fears of cancer recurrence are often worse in caregivers than in survivors themselves [69]. A similar effect could occur within the context of MS, relating to fears of relapse or progression. While a limited amount of research to date has explored this hypothesis, we know that close relatives of PwMS often experience anticipatory grief for what may lie ahead, as well as fears for the future [70]. Working to alleviate psychological distress in caregivers may therefore offer a means of reducing burden. This may include, for example, exploring ways to 
help both PwMS and caregivers cope with the uncertainty that comes hand-in-hand with the disease. More broadly, it may prove valuable to consider the role of psychological appraisals and illness perceptions in explaining how carers respond to the care situation when informing the provision of supports $[14 \bullet$, 55]. This may include mechanisms for fostering resilience, optimism and self-efficacy. Psychosocial interventions, such as programmes involving psycho-education, may offer an effective pathway for achieving this [71]. Indeed, simple measures, such as providing MS caregivers with appropriate information, may be a cost-effective way of reducing worries and perceived burden.

Examination of the wider social and contextual care environment can point to further ways in which burden might be reduced in MS caregivers. As stated previously, greater time spent caring (i.e. objective burden) is associated with greater subjective burden [25, 45]. Identifying ways of assisting carers with their tasks, including through the provision of respite care, would clearly alleviate burden. Furthermore, an analysis of data drawn from a cross-section of European countries suggests that a key factor in helping reduce the need for informal care is through the provision of community support $[17 \bullet \bullet]$. A need for social support is regularly expressed by MS caregivers, with many expressing a need to talk to somebody outside of their family and hospital staff [70]. Greater social support is associated with less experience of MS carer burnout [72], while a lack of support predicts carer depression, even after controlling for patient health status and disease severity [58]. This finding has been recently replicated in a variety of other carer populations [73].

Another potential way of providing support to caregivers is through the use of connective technologies. For example, MS caregivers may turn to internet support groups for information and support, with online peer interactions offering one means of decreasing feelings of loneliness and burden [74]. Such technologies may be particularly helpful in supporting carers who are both physically and socially isolated, whether this be due to routine or exceptional circumstances, such as the circumstances arising from the recent COVID-19 pandemic. It is likely that this situation has presented considerable challenges for those delivering care for PwMS, and future research in this area will need to explore how best to help caregivers cope in such contexts. Further developments and advances in technology, such as the provision of assistive technologies [75], are expected to offer innovative solutions for assisting carers in coming years.

\section{Towards a Detailed Understanding of MS Caregiver Experience}

While the work described above points to a number of means by which caregiver burden can be reduced, analysis of recent literature has revealed a number of additional interesting findings that can further deepen our understanding of the experience of caring for PwMS. While many studies examining MS caregiver burden have employed quantitative and survey-based techniques, in recent years, there has been a growing appreciation of the value of qualitative research in understanding the MS caregiving experience $[76 \bullet \cdot]$. This work sheds further light on the complex process of adjustment to the caring role [77], as well as dyadic adaptation from the perspective of both the caregiver and the PwMS [78]. Such research highlights that not all carers are the same, having different emotional reactions, needs and expectations $[79,80]$.

Qualitative research has also shown how caring involves more than simply burden and that it can lead to positive, as well as negative, experiences [81, 82]. Carers may discover more personal resources as they adapt to the caring role [70, $76 \bullet \bullet, 83]$, with supportive engagement and positive reframing reported as two examples of adaptive coping strategies [41]. MS caregivers may also adopt positive lifestyle modifications and embrace change through seeking additional knowledge and support from others [84, 85]. Another study found no relevant differences among MS caregivers and control groups in terms of life domains associated with happiness, goals and meanings [86], which argues against the assumption that caring negatively affects quality of life. Respondents here also reported a positive adjustment to the disease via the use of personal and family resources.

Such research implies that understanding the process of psychological adjustment is important when considering interventions that aim to support carers. This work also reflects the broader movement towards positive health psychology that has taken shape in recent years. We now appreciate that fostering certain traits, such as optimism, resilience and sense of purpose, can help people cope with chronic illness [87] and deal with the burden of care [14•]. Illness perceptions of both MS caregivers and patients have accordingly shown strong associations with well-being [41, 88•]. It is expected that future work on MS caregiving will further illuminate this relationship.

\section{Conclusions}

Our review highlights that MS caregiver burden is complex and represents only one aspect of the caregiving experience. MS is, in itself, a highly variable disease, and this variability in experience is also evident in the caregivers themselves. Crucially, while caring for a PwMS puts informal carers at risk of both objective and subjective burden, this does not always lead to negative outcomes. What is clear, however, is that informal care requires considerable time-commitment 
from caregivers and that they play a critical role in helping PwMS navigate the disease trajectory.

One potential limitation of MS caregiver research to date is that the findings are often interpreted from a clinical perspective, neglecting the wider range of sociocultural aspects that may crucially contribute to an individuals' functioning [86]. Recent work in the area however, particularly in qualitative research, suggests that attention is shifting towards appreciating the sociocultural context of care, offering promising directions for future research in the area. Emerging work also points to a number of interventions which may help decrease burden and enhance well-being among caregivers. Specifically, psychosocial interventions may help caregivers cope across a number of different areas, offering both practical and psychological support [58].

Based on our review, we make a number of recommendations in relation to future research in the area of MS caregivers. Firstly, future work should aim to appreciate the complexity of the MS caring experience, as well as the dyadic process of adjustment to living with the disease, which often results in shifting roles for both the carer and PwMS. Secondly, given the evidence that carers vary widely in age, background and relationship to the PwMS, viewing MS caregivers as a single homogenous group should be avoided. Providing supports for parental caregivers of paediatric MS, for example, may require a different approach than supports targeted at carers of adult PwMS [16]. Any proposed caregiver supports should be tailored in light of the various individual, care-recipient and contextual factors that are known to influence the caregiving experience. In particular, the psychosocial dimension of caring should receive more prominent acknowledgement. We argue that identifying means to alleviate possible psychological distress for both carers and PwMS is particularly important in helping people cope with the condition.

Finally, we expect that public and patient involvement (PPI) in research will become a prominent feature in driving research priorities forward in the area of MS, as well as in other healthcare contexts. In order to truly meet the needs of MS caregivers, we must first listen carefully to their experiences, as well as those of their care recipients. This involves centrally positioning them as co-designers in shaping future research agendas.

\section{Compliance with Ethical Guidelines}

Conflict of Interest The authors declare that they have no conflict of interests.

Human and Animal Rights All reported studies/experiments with human or animal subjects performed by the authors have been previously published and complied with all applicable ethical standards (including the Helsinki declaration and its amendments, institutional/national research committee standards and international/national/institutional guidelines).

\section{References}

Papers of particular interest, published recently, have been highlighted as:

- Of importance

- Of major importance

1. Brownlee WJ, Hardy TA, Fazekas F, Miller DH. Diagnosis of multiple sclerosis: progress and challenges. Lancet. 2017;389(10076):1336-46. https://doi.org/10.1016/s01406736(16)30959-x.

2. Banwell B, Arnold DL, Tillema J-M, Rocca MA, Filippi M, Weinstock-Guttman B, et al. MRI in the evaluation of pediatric multiple sclerosis. Neurology. 2016;87(9 Supplement 2):S88-96.

3. Duignan S, Brownlee W, Wassmer E, Hemingway C, Lim M, Ciccarelli $\mathrm{O}$, et al. Paediatric multiple sclerosis: a new era in diagnosis and treatment. Dev Med Child Neurol. 2019;61:1039-49.

4. Magyari M, Sorensen PS. The changing course of multiple sclerosis: rising incidence, change in geographic distribution, disease course, and prognosis. Curr Opin Neurol. 2019;32(3):320-6.

5. Barin L, Salmen A, Disanto G, Babačić H, Calabrese P, Chan A, et al. The disease burden of multiple sclerosis from the individual and population perspective: which symptoms matter most? Mult Scler Relat Disord. 2018;25:112-21.

6. Bayen E, Papeix C, Pradat-Diehl P, Lubetzki C, Joël M. Patterns of objective and subjective burden of informal caregivers in multiple sclerosis. Behav Neurol. 2015;2015:1-10.

7. Katsavos S, Artemiadis AK, Zacharis M, Argyrou P, Theotoka I, Chrysovitsanou $\mathrm{C}$, et al. Predicting caregiving status and caregivers' burden in multiple sclerosis. A short report. Neurol Res. 2017;39(1):13-5.

8. Sullivan AB, Miller D. Who is taking care of the caregiver? $\mathrm{J}$ Patient Exp. 2015;2(1):7-12. https://doi.org/10.1177/ 237437431500200103.

9. Tramonti F, Bonfiglio L, Bongioanni P, Belviso C, Fanciullacci C, Rossi B, et al. Caregiver burden and family functioning in different neurological diseases. Psychol Health Med. 2019;24(1):27-34.

10. Verbakel E, Tamlagsronning S, Winstone L, Fjaer E, Eikemo T. Informal care in Europe: findings from the European social survey (2014) special module on the social determinants of health. Eur J Pub Health. 2017;27:90-5. https://doi.org/10.1093/eurpub/ ckw229.

11. Gately M, Ladin K. Family and other caregivers. In: Daaleman T, Helton M, editors. Chronic illness care. Cham: Springer; 2018.

12.• Opara J, Brola W. Quality of life and burden in caregivers of multiple sclerosis patients. Physiotherapy and Health Activity. 2018;25(1):9-16. This review highlights the various objective and subjective burdens that are associated with MS caregiving.

13. Merck. Living with multiple sclerosis: the carer's perspective. 2018. Available at https://www.merckgroup.com/es-es/informes/Livingwith-MS-Carers-Perspective.pdf

14. Maguire R, Hanly P, Maguire P. Beyond care burden: associations between positive psychological appraisals and well-being among informal caregivers in Europe. Qual Life Res. 2019;28:2135-46. This analysis reveals a variety of different factors and their association with wellbeing in a European caregiver sample. https://doi.org/10.1007/s11136-019-02122-y.

15. Roth D, Fredman L, Haley W. Informal caregiving and its impact on health: a reappraisal from population-based studies. Gerontologist. 2015;55(2):309-19. https://doi.org/10.1093/geront/ gnu177.

16. Maguire R, Kasilingam E, Kriauzaite N. Caring for children and adolescents with multiple sclerosis: exploring the unmet needs and 
existing supports for paediatric multiple sclerosis caregivers. European Multiple Sclerosis Platform. 2019. Available at http:// www.emsp.org/projects/caregivers-of-paediatric-ms/

17.• Kobelt G, Thompson A, Berg J, Gannedahl M, Eriksson J, Group MS, Platform EMS. New insights into the burden and costs of multiple sclerosis in Europe. Mult Scler J. 2017;23(8):1123-36. Large scale PwMS-reported study including an analysis of care provision, showing economic burden of MS.

18. Hategeka C, Traboulsee A, McMullen K, Lynd LD. Stigma in multiple sclerosis: association with work productivity loss, healthrelated quality of life and caregivers' burden (P3.332). AAN Enterprises. 2017. https://n.neurology.org/content/88/16 Supplement/P3.332.short.

19. Wallin MT, Culpepper WJ, Nichols E, Bhutta ZA, Gebrehiwot TT, Hay SI, et al. Global, regional, and national burden of multiple sclerosis 1990-2016: a systematic analysis for the global burden of disease study 2016. Lancet Neurol. 2019;18(3):269-85.

20. Giordano A, Cimino V, Campanella A, Morone G, Fusco A, Farinotti M, et al. Low quality of life and psychological wellbeing contrast with moderate perceived burden in carers of people with severe multiple sclerosis. J Neurol Sci. 2016;366:139-45.

21. Wallin MT, Culpepper WJ, Campbell JD, Nelson LM, LangerGould A, Marrie RA, et al. The prevalence of MS in the United States: a population-based estimate using health claims data. Neurology. 2019;92(10):e1029-40.

22.• McKenzie T, Quig ME, Tyry T, Marrie RA, Cutter G, Shearin E, et al. Care partners and multiple sclerosis: differential effect on men and women. Int J MS Care. 2015;17(6):253-60. Analysis of 1,333 caregivers illustrating the burden of care, including psychological and physical health concerns of caregivers.

23. Petrikis P, Baldouma A, Katsanos AH, Konitsiotis S, Giannopoulos S. Quality of life and emotional strain in caregivers of patients with multiple sclerosis. J Clin Neurol. 2019;15(1):77-83.

24. Perrin Ross A. Management of multiple sclerosis. Am J Manag Care. 2013;19(16 Suppl):s301-6.

25. Özmen S, Yurttaș A. Determination of care burden of caregivers of patients with multiple sclerosis in Turkey. Behav Neurol. 2018;2018:1-7.

26. Perrin PB, Panyavin I, Morlett Paredes A, Aguayo A, Macias MA, Rabago B, et al. A disproportionate burden of care: gender differences in mental health, health-related quality of life, and social support in Mexican multiple sclerosis caregivers. Behav Neurol. 2015;2015:1-9.

27. Manouchehrinia A, Westerlind H, Kingwell E, Zhu F, Carruthers R, Ramanujam R, et al. Age related multiple sclerosis severity score: disability ranked by age. Mult Scler J. 2017;23(14):1938-46.

28. Buhse M, Della Ratta C, Galiczewski J, Eckardt P. Caregivers of older persons with multiple sclerosis: determinants of health-related quality of life. J Neurosci Nurs. 2015;47(2):E2-E12.

29. Gibson J, Colton F, Sanderson C. Young carers. Br J Gen Pract. 2019;69(687):504

30. Mauseth T, Hjälmhult E. Adolescents' experiences on coping with parental multiple sclerosis: a grounded theory study. J Clin Nurs. 2016;25(5-6):856-65.

31. Moberg JY, Larsen D, Brødsgaard A. Striving for balance between caring and restraint: young adults' experiences with parental multiple sclerosis. J Clin Nurs. 2017;26(9-10):1363-74.

32. Cross TP, Shanks AK, Duffy LV, et al Families' experience of pediatric onset multiple sclerosis. J Child Adolesc Trauma. 2019;12:425-35. https://doi.org/10.1007/s40653-018-0243-7.

33. Hebert D, Geisthardt $\mathrm{C}$, Hoffman $\mathrm{H}$. Insights and recommendations from parents receiving a diagnosis of pediatric multiple sclerosis for their child. J Child Neurol. 2019;34(8):464-71. https://doi.org/10. $1177 / 0883073819842420$.
34. Hinton D, Kirk S. Living with uncertainty and hope: a qualitative study exploring parents' experiences of living with childhood multiple sclerosis. Chronic Illn. 2017;13(2):88-99.

35. Uccelli MM. The impact of multiple sclerosis on family members: a review of the literature. Neurodegener Dis Manag. 2014;4(2):17785.

36. Pooyania S, Lobchuk M, Chernomas W, Marrie RA. Examining the relationship between family caregivers' emotional states and ability to empathize with patients with multiple sclerosis: a pilot study. Int J MS Care. 2016;18(3):122-8.

37. Calvo-Perxas L, Vilalta-Franch J, Litwin H, Turro-Garriga O, Mira $\mathrm{P}$, Garre-Olmo J. What seems to matter in public policy and the health of informal caregivers? A cross-sectional study in 12 European countries. PLoS One. 2018;13(3):e0194232. https://doi. org/10.1371/journal.pone.0194232.

38. Kaschowitz J, Brandt M. Health effects of informal caregiving across Europe: a longitudinal approach. Soc Sci Med. 2017;173: 72-80. https://doi.org/10.1016/j.socscimed.2016.11.036.

39. Rafnsson S, Shankar A, Steptoe A. Informal caregiving transitions, subjective well-being and depressed mood: findings from the English longitudinal study of ageing. Aging Ment Health. 2017;21(1):104-12. https://doi.org/10.1080/13607863.2015. 1088510.

40. Kudra A, Lees C, Morrell-Scott N. Measuring carer burden in informal carers of patients with long-term conditions. Br J Community Nurs. 2017;22(5):230-6.

41. Bassi M, Cilia S, Falautano M, Grobberio M, Negri L, Niccolai C, et al. The caring experience in multiple sclerosis: caregiving tasks, coping strategies and psychological well-being. Health \& Social Care in the Community. 2019;28(1):236-46. https://doi.org/10. 1111/hsc. 12858 .

42. Carroll S, Chalder T, Hemingway C, Heyman I, Moss-Morris R. "It feels like wearing a giant sandbag." adolescent and parent perceptions of fatigue in paediatric multiple sclerosis. Eur J Paediatr Neurol. 2016;20(6):938-45. https://doi.org/10.1016/j.ejpn.2016. 06.004 .

43. Harris YC. A qualitative descriptive study exploring the adaptation of families of children with multiple sclerosis from the perspective of caregivers. Dissertation. Birmingham: The University of Alabama; 2018.

44. García-Domínguez JM, Maurino J, Martínez-Ginés ML, Carmona $\mathrm{O}$, Caminero AB, Medrano N, et al. Economic burden of multiple sclerosis in a population with low physical disability. BMC Public Health. 2019;19(1):609.

45. Meca-Lallana J, Mendibe M, Hernández-Clares R, Caminero AB, Mallada-Frechin J, Dávila-Gonzalez P, et al. Predictors of burden and depression among caregivers of relapsing-remitting MS patients in Spain: MS feeling study. Neurodegener Dis Manag. 2016;6(4):277-87.

46. Macias Islas MA, Ciampi E. Assessment and impact of cognitive impairment in multiple sclerosis: an overview. Biomedicines. 2019;7(1). https://doi.org/10.3390/biomedicines7010022.

47. Scholten EW, Hillebregt CF, Ketelaar M, Visser-Meily JM, Post MW. Measures used to assess impact of providing care among informal caregivers of persons with stroke, spinal cord injury, or amputation: a systematic review. Disabil Rehabil. 2019:1-27. https://doi.org/10.1080/09638288.2019.1641847.

48. Zarit S, Orr NK, Zarit JM. The hidden victims of Alzheimer's disease: families under stress. New York: NYU Press; 1985.

49. Bédard M, Molloy DW, Squire L, Dubois S, Lever JA, O'Donnell $M$. The Zarit burden interview: a new short version and screening version. The Gerontologist. 2001;41(5):652-7.

50. Benito-León J, Rivera-Navarro J, Guerrero AL, de las Heras V, Balseiro J, Rodríguez E, et al. The CAREQOL-MS was a useful instrument to measure caregiver quality of life in multiple sclerosis. J Clin Epidemiol. 2011;64(6):675-86. 
51. Given CW, Given B, Stommel M, Collins C, King S, Franklin S. The caregiver reaction assessment (CRA) for caregivers to persons with chronic physical and mental impairments. Res Nurs Health. 1992;15(4):271-83.

52. Sadak T, Korpak A, Wright JD, Lee MK, Noel M, Buckwalter K, et al. Psychometric evaluation of Kingston caregiver stress scale. Clin Gerontol. 2017;40(4):268-80.

53. Litzelman K, Kent E, Mollica M, Rowland J. How does caregiver well-being relate to perceived quality of care in patients with cancer? Exploring associations and pathways. J Clin Oncol. 2016;34(29):3554. https://doi.org/10.1200/JCO.2016.67.3434.

54. Santos M, Sousa C, Pereira M, Pereira MG. Quality of life in patients with multiple sclerosis: a study with patients and caregivers. Disabil Health J. 2019;12:628-34. https://doi.org/10.1016/j.dhjo. 2019.03.007.

55. Gérain P, Zech E. Informal caregiver burnout? Development of a theoretical framework to understand the impact of caregiving. Front Psychol. 2019;10:1748.

56. Ertekin O, Ozakbas S, Idiman E. Caregiver burden, quality of life and walking ability in different disability levels of multiple sclerosis. NeuroRehabilitation. 2014;34(2):313-21. https://doi.org/10. 3233/nre-131037.

57. van der Hiele K, van Gorp D, Heerings M, Jongen P, van der Klink $\mathrm{J}$, Beenakker E, et al. Caregiver strain among life partners of persons with mild disability due to relapsing-remitting multiple sclerosis. Mult Scler Relat Disord. 2019;31:5-11.

58. Bambara JK, Turner AP, Williams RM, Haselkorn JK. Social support and depressive symptoms among caregivers of veterans with multiple sclerosis. Rehabil Psychol. 2014;59(2):230-5.

59. Labiano-Fontcuberta A, Mitchell AJ, Moreno-García S, BenitoLeón J. Anxiety and depressive symptoms in caregivers of multiple sclerosis patients: the role of information processing speed impairment. J Neurol Sci. 2015;349(1-2):220-5.

60. Labiano-Fontcuberta A, Mitchell AJ, Moreno-García S, BenitoLeón J. Cognitive impairment in patients with multiple sclerosis predicts worse caregiver's health-related quality of life. Mult Scler J. 2014;20(13):1769-79.

61. Tzitzika M, Lampridis E, Kalamaras D. Relational satisfaction of partner/spousal informal caregivers of multiple sclerosis patients: the role of relational commitment, caregiving burden, and prorelational behavioral tendencies. Int J MS Care. 2019;22:60-6.

62. Lee E-J, Pieczynski J, DeDios-Stern S, Simonetti C, Lee GK. Gender differences in caregiver strain, needs for support, social support, and quality of life among spousal caregivers of persons with multiple sclerosis. Work. 2015;52(4):777-87.

63. Rollero C. The experience of men caring for a partner with multiple sclerosis. J Nurs Scholarsh. 2016;48(5):482-9.

64. Balfe M, Keohane K, O'Brien K, Gooberman-Hill R, Maguire R, Hanly P, et al. In a bad place: carers of patients with head and neck cancer experiences of travelling for cancer treatment. Eur J Oncol Nurs. 2017;30:29-34. https://doi.org/10.1016/j.ejon.2017.07.001.

65. Boeschoten RE, Braamse AM, Beekman AT, Cuijpers P, van Oppen P, Dekker J, et al. Prevalence of depression and anxiety in multiple sclerosis: a systematic review and meta-analysis. J Neurol Sci. 2017;372:331-41.

66. Kalb R, Feinstein A, Rohrig A, Sankary L, Willis A. Depression and suicidality in multiple sclerosis: red flags, management strategies, and ethical considerations. Curr Neurol Neurosci Rep. 2019;19(10):77.

67. Alschuler KN, Beier ML. Intolerance of uncertainty: shaping an agenda for research on coping with multiple sclerosis. Int J MS Care. 2015;17(4):153-8. https://doi.org/10.7224/1537-2073.2014044.

68. Macías-Delgado Y, Pedraza-Núñez H, Jiménez-Morales R, PérezRodríguez M, Valle-Solano RC, Fundara-Díaz R. Burden in primary caregivers of patients with multiple sclerosis: their relationship with depression and anxiety. Revista Mexicana de Neurociencia. 2014;15(2):81-6.

69. Maguire R, Hanly P, Balfe M, Timmons A, Hyland P, O'Sullivan E, et al. Worry in head and neck cancer caregivers the role of survivor factors, care-related stressors, and loneliness in predicting fear of recurrence. Nurs Res. 2017;66(4):295-303. https://doi.org/10. 1097/NNR.0000000000000223.

70. Grimby A, Johansson Å, Johansson U. Anticipatory grief among close relatives of patients with ALS and MS. Psychology and Behavioral Sciences. 2015;4(3):125-31.

71. Pahlavanzadeh S, Dalvi-Isfahani F, Alimohammadi N, Chitsaz A. The effect of group psycho-education program on the burden of family caregivers with multiple sclerosis patients in Isfahan in 2013-2014. Iran J Nurs Midwifery Res. 2015;20(4):420-5.

72. Dayapoğlu N, Tan M. The care burden and social support levels of caregivers of patients with multiple sclerosis. Kontakt. 2017;19(1): e17-23.

73. Safavi R, Berry K, Wearden A. Expressed emotion in relatives of persons with dementia: a systematic review and meta-analysis. Aging Ment Health. 2017;21(2):113-24.

74. Sillence E, Hardy C, Briggs P, Harris PR. How do carers of people with multiple sclerosis engage with websites containing the personal experiences of other carers and patients? Health Informatics J. 2016;22(4):1045-54.

75. Madara Marasinghe $K$. Assistive technologies in reducing caregiver burden among informal caregivers of older adults: a systematic review. Disabil Rehabil Assist Technol. 2016;11(5):353-60.

76.• Appleton D, Robertson N, Mitchell L, Lesley R. Our disease: a qualitative meta-synthesis of the experiences of spousal/partner caregivers of people with multiple sclerosis. Scand J Caring Sci. 2018;32(4):1262-78. This paper provides a review of qualitative studies on MS caregiver experience and makes some suggestions for supportive interventions that might be effective for spousal caregivers.

77. Carling A, Nilsagård Y, Forsberg A. Making it work: experience of living with a person who falls due to multiple sclerosis. Disabil Rehabil. 2018;42(7):940-7. https://doi.org/10.1080/09638288. 2018.1514078.

78. Wawrziczny E, Corrairie A, Antoine P. Relapsing-remitting multiple sclerosis: an interpretative phenomenological analysis of dyadic dynamics. Disabil Rehabil. 2019:1-9. https://doi.org/10.1080/ 09638288.2019.1617794.

79. Ebrahimi H, Hassankhani H, Namdar H, Khodadadi E, Ferguson C. Experiences of Iranian family caregivers supporting individuals with multiple sclerosis: a qualitative study. International Journal of Medical Research \& Health Sciences. 2016;5(9):174-82.

80. Gafari S, Khoshknab MF, Nourozi K, Mohamadi E. Informal caregivers' experiences of caring of multiple sclerosis patients: a qualitative study. Iran J Nurs Midwifery Res. 2017;22(3):243-7.

81. Killner L, Soundy A, Soundy A, Birmingham WM. Motivation and experiences of role transition in spousal caregivers of people with multiple sclerosisis. International Journal of Therapy and Rehabilitation. 2018;25(8):405-13. https://doi.org/10.12968/ijtr. 2018.25.8.405.

82. Topcu G, Buchanan H, Aubeeluck A, Garip G. Caregiving in multiple sclerosis and quality of life: a meta-synthesis of qualitative research. Psychol Health. 2016;31(6):693-710.

83. du Plooy DR, Pretorius C. The caregiver experience: a South African perspective on caring for people with multiple sclerosis. J Psychol Afr. 2014;24(4):361-9.

84. Neate SL, Taylor KL, Jelinek GA, De Livera AM, Brown CR, Weiland TJ. Psychological shift in partners of people with multiple sclerosis who undertake lifestyle modification: an interpretive phenomenological study. Front Psychol. 2018;9:15.

85. Neate SL, Taylor KL, Jelinek GA, De Livera AM, Brown CR, Weiland TJ. Taking active steps: changes made by partners of 
people with multiple sclerosis who undertake lifestyle modification. PLoS One. 2019;14(2):e0212422. https://doi.org/10.1371/journal. pone. 0212422

86. Delle Fave A, Bassi M, Allegri B, Cilia S, Falautano M, Goretti B, et al. Beyond disease: happiness, goals, and meanings among persons with multiple sclerosis and their caregivers. Front Psychol. 2017;8:2216.

87. Maguire R, Hanly P, Maguire P. Living well with chronic illness: how social support, loneliness and psychological appraisals relate to well-being in a population-based European sample. J Health Psychol. 2019:1359105319883923. https://doi.org/10.1177/ 1359105319883923.
88. Bassi M, Falautano M, Cilia S, Goretti B, Grobberio M, Pattini M, et al. Illness perception and well-being among persons with multiple sclerosis and their caregivers. J Clin Psychol Med Settings. 2016;23(1):33-52. This study of 680 MS caregivers gives an overview of caregiving activities and coping strategies, and illustrates MS caring does not involve only negative experiences.

This article is PPI driven, having been led by a person with MS (RM).

Publisher's Note Springer Nature remains neutral with regard to jurisdictional claims in published maps and institutional affiliations. 